Original Article

\title{
FORMULATION AND EVALUATION OF METFORMIN HYDROCHLORIDE LOADED FLOATING MICROSPHERES
}

\author{
SHIKHA KESHARVANI ${ }^{*}$, PANKAJ KUMAR JAISWAL ${ }^{1}$, ALOK MUKERJEE1, AMIT KUMAR SINGH'1
}

1United Institute of Pharmacy, Naini, Allahabad, Uttar Pradesh, India 211010

Email: shikhakeserwani55555@gmail.com

Received: 26 Jul 2019, Revised and Accepted: 16 Dec 2019

\section{ABSTRACT}

Objective: The main objective of this study was to develop and evaluate the eudragit and HPMC coated metformin hydrochloride floating microspheres, in which HPMC helps in floating and eudragit as a coating material for a site-specific drug release in a controlled manner and the active moiety metformin used as anti-hyperglycemic agent.

Methods: The floating microsphere was prepared by the solvent evaporation method incorporating metformin as a model drug. The prepared floating microsphere were characterized for particle size, \%yield, drug loading and entrapment efficiency, compatibility study, \%buoyancy, surface morphology and In vitro drug release and release kinetics.

Results: The result metformin loaded floating microsphere was successfully prepared and the particle size range from $397 \pm 23.22$ to $595 \pm 15.82 \mu \mathrm{m}$ the entrapment efficiency range from $83.49 \pm 1.33$ to $60.02 \pm 1.65 \%$ and drug loading capacity range from $14.3 \pm 0.54$ to $13.31 \pm 0.47 \%$ and $\%$ buoyancy range from $85.67 \pm 0.58$ to $80.67 \pm 1.15 \%$. The FT-IR and X-RD analysis confirmed that no any interaction between drug and excipient, and surface morphology confirmed those particles are sphere. The floating microsphere show maximum $96 \%$ drug release in $\mathrm{pH} 0.1 \mathrm{~N}$ HCL and follow the Korsmeyer peppas model of the super case-2 transport mechanism.

Conclusion: These results suggest that metformin loaded floating microspheres could be retain in stomach for long time and give site specific drug release in controlled manner.

Keywords: Floating capability, Therapeutic Response, Eudragit and Metformin

(C) 2020 The Authors. Published by Innovare Academic Sciences Pvt Ltd. This is an open access article under the CC BY license (http://creativecommons.org/licenses/by/4.0/) DOI: http://dx.doi.org/10.22159/ijpps.2020v12i2.35099. Journal homepage: https://innovareacademics.in/journals/index.php/ijpps

\section{INTRODUCTION}

Most preferred route for drug delivery is the oral route due to its patient compliance and easiness of ingestion and cost-effectiveness. Many different techniques have been developed like tablet capsule syrups etc for delivery of a significant amount of drug at a specific site and time prearranged and systematic manner but this route has numerous physiological problems, like-easily bypass through GIT at major absorption zone (stomach and upper part of intestine) due to high density and low density retention time resulting incomplete drug release and low efficacy of drug unpredictable absorption due to degradation of drug by stomach acid and enzyme [1], hence the site specific drug delivery for diabetic through oral route is also most challenging task for researchers. So these difficulties provoked the investigators to develop a DDS known as gastro retentive floating microspheres which performs its actions i.e. its therapeutically active plasma concentration of drug for prolonged period of time, by minimizing the dosing criteria and minimizing the fluctuations in plasma concentration of drug by the pharmacological effect of the drug in a systemic and controlled way. After oral delivery of gastro retentive floating microspheres, the drug reserved in to the stomach and performs the action of drug release in a well-ordered manner, so that the delivery of drug is continuous at its absorption sites in GIT (gastrointestinal tract) [2]. The floating systems are low-density systems that have sufficient buoyancy to float over the gastric content and remain buoyant the stomach without affecting the gastric emptying rate for a prolonged period of time which causes the inadequate release of drug at the absorption site [3]. Over the last minority decades, several gastro-retentive drug delivery systems being intended, including high-density systems that is retain in the lower part of the stomach [4], lower density which cause buoyancy in gastric-juice $[5,6]$, mucoadhesive systems that cause a bio-adhesion to stomach mucosa $[7,8]$, unfoldable, extendible, or swellable systems which can restriction of the emptying dosage forms through the pyloric sphincter $[9,10]$, super- porous hydrogel system [11], magnetic system, etc [12]. Here we are developing lower density system that's floating microsphere, is prepared by solvent evaporation method incorporating metformin as a model drug. The active moiety metformin is an antihyperglycemic agent that's fast soluble in stomach $\mathrm{pH}$ so the drug immediately released and not remains to specific site for long time. To overcome these problems, we prepare eudragit coated, HPMC and metformin hydrochloride loaded floating microspheres [13]. The HPMC helps in floating that helps in long-time retention of microspheres into stomach and eudragit as a coating material to prevent the fast solubility of metformin hydrochloride in acidic $\mathrm{pH}$ and give site specific drug release in a controlled manner. Then metformin hydrochloride easily reduce the production from hepatic and glucose absorption from the intestine, and improved sensitivity of insulin by increasing tangential uptake of glucose and its utilization. In this process Metformin decreases blood glucose levels. The recent study describes the various Gastro-retentive approaches which are newly developed into leading methodologies in the field of site-specific orally controlled release drug delivery systems.

\section{MATERIALS AND METHODS}

Metformin hydrochloride was a gift sample from the Sun Pharmaceutical Industries Ltd., Vadodara, India. HPMC was procured from the LOBA Cheme Pvt. Ltd., Mumbai and the eudragitS100 was procured from the Central Drug House Pvt. Ltd., New Delhi. All the chemicals and solvent used in the study were of analytical grade.

\section{Preparation of floating microspheres}

Floating microspheres were prepared by emulsification $(\mathrm{o} / \mathrm{w})$ solvent evaporation method using a varying concentration of polymers (HPMC, Eudragit S100). The polymer solution was prepared by dissolving polymers (HPMC, EudragitS100) in different ratio of the mixture of solvents (ethanol, dichloromethane) with 
vigorous shaking. The aqueous solution containing tween80 was taken in another beaker. The polymer solution was then added manually dropwise into the aqueous solution through a syringe (needle size 22 gauges) under continuous stirring at $100 \mathrm{rpm}$. The added droplets were kept dispersed in the aqueous solution for 30 min. to complete the reaction and to produce spherical rigid microspheres. The formed microspheres were collected and washed with distilled water 2-3 times and air-dried for $24 \mathrm{~h}[14,15]$. The drug-loaded microspheres shown in fig. 1 were prepared by the solvent evaporation method according to the above-described method by varying concentration of polymers (HPMC, eudragit) and drug. The compositions of floating microsphere are given in table 1.

Table 1: Composition of the floating microsphere of each batch, HPMC-hydroxyl propyl methylcellulose, DCM-dichloromethane

\begin{tabular}{lllllll}
\hline $\begin{array}{l}\text { Trial } \\
\text { No. }\end{array}$ & Formulation & $\begin{array}{l}\text { HPMC } \\
\text { (mg) }\end{array}$ & $\begin{array}{l}\text { Eudragit S100 } \\
\text { (mg) }\end{array}$ & $\begin{array}{l}\text { DCM+Ethanol } \\
\text { (ml)(1:3) }\end{array}$ & $\begin{array}{l}\text { Drug } \\
\text { (mg) }\end{array}$ & $\begin{array}{l}\text { Aqueous phase containing 1\% Tween 80 } \\
\text { (m) }\end{array}$ \\
\hline 01 & Formulation-1 & 400 & 100 & 20 & 0 & 150 \\
02 & Formulation-2 & 500 & 100 & 20 & 0 & 150 \\
03 & Formulation-3 & 600 & 100 & 20 & 0 & 150 \\
04 & Formulation-4 & 700 & 100 & 20 & 0 & 150 \\
05 & Formulation-5 & 800 & 100 & 20 & 0 & 150 \\
06 & Formulation-6 & 600 & 100 & 20 & 100 & 150 \\
07 & Formulation-7 & 700 & 100 & 20 & 100 & 150 \\
08 & Formulation-8 & 700 & 100 & 20 & 150 & 150 \\
09 & Formulation-9 & 700 & 100 & 20 & 200 & 150 \\
10 & Formulation10 & 700 & 100 & & \\
\hline
\end{tabular}

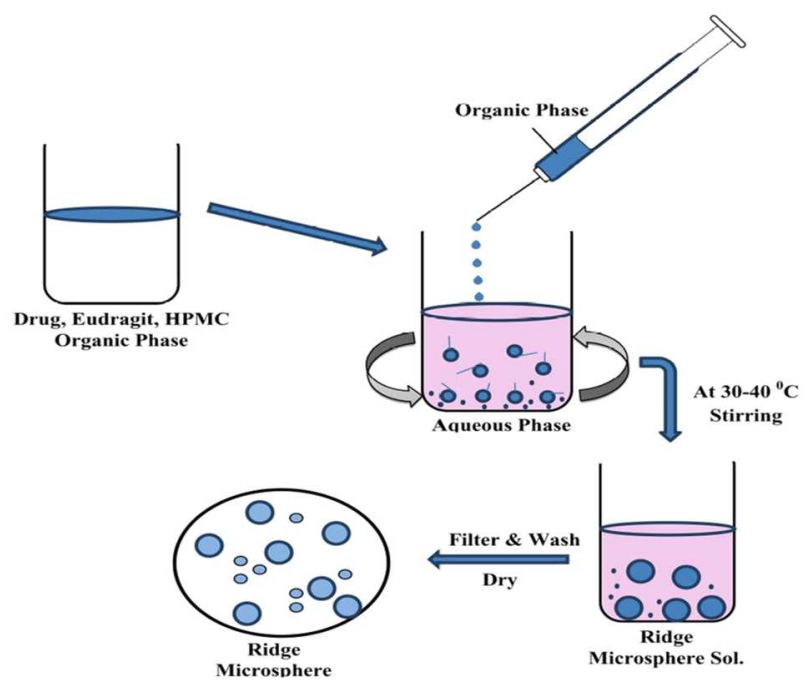

Fig. 1: Preparation of floating microspheres

\section{Particle size}

Particle size of the blank and metformin hydrochloride loaded microsphere was determined by optical microscopy method using a compound microscope (Olympus India) equipped with ocular and calibrated stage micrometers. After the calibration of an ocular micrometer by placing the ocular lens after that the focusing on the object to be measured and determine the size in ocular units, then placing the samples on the slide and measuring the size of microspheres [16].

$$
\text { One ocular unit }=\frac{\text { Division }(\mathrm{mm}) \text { stage micrometer }}{\text { Ocular micrometer division }} \times 100 \mu \mathrm{m} / \mathrm{mm}
$$

\section{Percentage yield}

The percentage yield of the blank and metformin hydrochloride microspheres preparation was obtained by applying the mentioned formula [17].

$$
\% \text { Yield }=\frac{\text { Weight of the microspheres obtained }}{\text { Total weight of the drug and excipients }} \times 100
$$

\section{Percentage buoyancy}

The percentage buoyancy of the microspheres was calculated by the $500 \mathrm{mg}$ of the microspheres place in a USP mentioned type II instrument filled with $900 \mathrm{ml}$ of 0.1 NHCL which consists of tween 80 with stirring for $12 \mathrm{~h}$ at $50 \mathrm{rpm}$. After $12 \mathrm{~h}$ the particles of floating nature and the precipitated particles are taken out and dried and weight. Percentage buoyancy was determined by the following formula [18].

$$
\text { Percentage buoyancy }=\frac{w F}{w f+w s} \times 100
$$

Where-wf $=$ Weight of floating particles, ws $=$ Weight of settled particles

\section{Determination of drug content of microspheres}

The $50 \mathrm{mg}$ microspheres were dissolved in few $\mathrm{ml}$ of ethanol and dilute with $50 \mathrm{ml}$ of $0.1 \mathrm{~N}$ hydrochloric acid in a $100 \mathrm{ml}$ volumetric flask and mixture was shaken until a formulation was destructed. The solution was passed through W. F. P (No. 41). Then diluted with

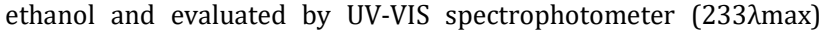
using a UV-1800 Shimadzu spectrophotometer.

$$
\text { Loading drug content }=\frac{\text { Weight of drug in the microsphere }}{\text { Total weight of microsphere }} \times 100
$$

\section{Drug entrapment efficiency}

Entrapment efficiency of microspheres was determined by extraction of drug from the microspheres. In a typical procedure, 50 mg of dried microsphere were crushed in a mortar and pestle, and the fine microspheres dissolved in few $\mathrm{ml}$ of Ethanol and dilute with $50 \mathrm{ml}$ of $0.1 \mathrm{~N} \mathrm{HCL}$ for $24 \mathrm{~h}$. After $24 \mathrm{~h}$, the solution was passed 
through a $0.45 \mu \mathrm{m}$ filter and the conc. of the metformin hydrochloride present in the filtrate was evaluated spectrophotometrically at $233 \mathrm{~nm}$ using UV-Visible Spectrophotometer (Shimadzu, UV-1800, Japan) with respect to $0.1 \mathrm{~N}$ HCL as blank [19].

$$
\text { Drug entrapment efficiency }=\frac{\text { Weight of drud in microspheres }}{\text { Weight of the fed drug }} \times 100
$$

\section{Micromeritic properties of microspheres}

Prepared microspheres were evaluated for their micrometric properties such as as bulk density, tapped density, compressibility index, and angle of repose.

\section{- Bulk density}

Bulk density of microspheres was evaluated by the ratio of the untapped microsphere weight and its volume it's obtained by this formula [20].

$$
\text { Bulk density }=\frac{\mathbf{M}}{\mathbf{V}^{\circ}}
$$

Where $\mathrm{M}=$ Weight of microsphere sample, $\mathrm{V}^{\circ}=$ Apparent volume of the microsphere

\section{- Tapped density}

The tapped density was calculated by mechanical tapping of a graduated measuring cylinder which consists of the microspheres. It is the ratio of the initial microsphere volume with tapped volume of microsphere (after tapping) [21].

$$
\text { Tapped density }=\frac{\text { Weight of microspheres }}{\text { Final tapped volume of the microspheres }}
$$

\section{- Compressibility index}

The compressibility index is a tendency of microspheres to be compressed. It's calculated by this formula.

$$
\mathrm{CI}=\frac{\mathrm{TD}-\mathrm{BD}}{\mathrm{TD}} \times 100
$$

Where-TD = Tapped Density, BD = Bulk Density

\section{- Angle of repose}

This property was evaluated by the maximum angle possible between the surface of the pile of the microspheres and the horizontal plane; it's obtained by the funnel in a fixed position.

$$
\theta=\tan ^{-1}(\mathrm{~h} / \mathrm{r})
$$

\section{Drug polymer compatibility study}

Drug-polymer interaction studies were carried out by using FT-IR and XRD analysis.

\section{- $\quad$ FTIR study}

The FT-IR study of blank and drug-loaded formulations was performed to find any possible drug-polymer interaction using Fourier Transform Infra-red spectrometer (Bruker Alpha, Germany) in the frequency range of $4000-400 \mathrm{~cm}^{-1}[22]$.

\section{- XRD analysis}

The effect of crystallinity of drug and excipient on formulation was evaluated by using XRD analysis. The XRD patterns of blank and drug-loaded microspheres were recorded using X-ray Diffractometer (Rigaku-Ultima IV, Japan), using Cu radiation, a voltage of $40 \mathrm{kV}$ and a current of $30 \mathrm{~mA}$. The scanning speed employed was $2 \% \mathrm{~min}$ over the range of $10^{\circ}$ to $90^{\circ}$ diffraction angle [23].

\section{Morphological characterization}

The shape and size of the metformin hydrochloride-loaded microsphere were assessed by SEM. The samples were prepared by mounting the sample onto a metal stub with adhesive tape on both sides. Carbon coating was done in a high vacuum evaporator. Then the process of scanning and taking images was done [24].

\section{In vitro drug release study}

The In vitro drug release studies were performed by USP dissolution Test Apparatus Type 1 (Basket Type) at $100 \mathrm{rpm}$ in $900 \mathrm{ml}$ of dissolution medium and at a temperature of $37{ }^{\circ} \mathrm{C} \pm 0.5{ }^{\circ} \mathrm{C}$. An accurately weighed amount of prepared microspheres (equivalent to $100 \mathrm{mg}$ ) were used for the study. The test performed in $0.1 \mathrm{~N} \mathrm{HCl}$ as dissolution media. After a time interval of $0.5,1,2,3,4,5,6,7,8,9,10$, 12 and $24 \mathrm{~h}, 5 \mathrm{ml}$ of sample was withdrawn from dissolution media and replaced by $5 \mathrm{ml}$ of the fresh medium. The sample was passed through W. F. P. and assayed spectrophotometrically at $233 \mathrm{~nm}$ using a UV-Visible spectrophotometer (Shimadzu, UV-1800, Japan) [25, 26].

\section{In vitro drug release kinetics}

To investigate the drug release mechanism from the microspheres, in vitro drug release data was fitted to various kinetic models like zero order, first order, Higuchi equation, and Korsmeyer-Peppas equation. By comparing the $r$ values obtained, the best fit model was selected [27-30].

\section{- Zero-order kinetics}

Dissolution of the drug from the dosage forms that do not disaggregate and release the drug slowly can be represented by the following equation.

$\mathrm{Qt}=\mathrm{Q} 0+\mathrm{K} 0 \mathrm{t}$

Where, Qt is the amount of drug dissolved in time $t, \mathrm{Q} 0$ is the Initial amount of drug in the solution and $\mathrm{K} 0$ is the zero-order release rate constant. To study the release kinetics, data obtained from the in vitro drug release studies were plotted as $\%$ CDR vs. Time.

\section{- $\quad$ First-order kinetics}

This model has been used to describe the absorption or elimination of drugs. The release of the drug which followed first-order kinetics can be expressed by the following equation.

$$
\log \mathrm{C}=\log \mathrm{C}_{0}-\frac{\mathrm{Kt}}{2.303}
$$

Where $\mathrm{C}$ is the amount of drug release in time $t, \mathrm{C} 0$ is the amount of drug in the solution and $\mathrm{K}$ is the first-order release rate constant. To study the release kinetic data obtained from the in vitro drug release studies were plotted as $\log \%$ drug unreleased vs. Time.

\section{- Higuchi model}

This model used to describe the release of water-soluble and low water-soluble drugs from the solid or semisolid matrix system. Mathematical expressions were obtained for drug particles dispersed in uniform matrix behaving as the diffusion media. The mathematical expression of Higuchi model is as follows:

$$
\mathrm{Q} t=\mathrm{KH} \cdot \mathrm{t}^{1 / 2}
$$

Whereas Qt is the amount of drug release in time $t$ and $\mathrm{KH}$ is the Higuchi dissolution constant. To study the release kinetics, data obtained from the in vitro drug release were plotted as \% CDR vs Square root of time.

\section{- Korsmeyer-peppas model}

This model used to describe the release of drugs from the polymeric system when the release mechanism is not well known or more than one type of release phenomena could be involved. The equation of the Korsmeyer-Peppas model is as follows:

$$
\frac{\mathrm{Mt}}{\mathrm{M} \infty}=\mathrm{Kt}^{\mathrm{n}}
$$

Where $\frac{\mathrm{Mt}}{\mathrm{M} \infty}$ is the fraction of drug release, $\mathrm{K}$ is the release rate constant, $t$ is the release time and $n$ is the release exponent

To study the release kinetics, data obtained from the in vitro drug release were plotted $\log \%$ CDR vs. Time. Peppas used this n-value in order to characterize different release mechanisms as given in table 2 . 
Table 2: Different release mechanism

\begin{tabular}{lll}
\hline Diffusion release exponent (n) & Overall drug diffusion mechanism & Time-dependence of drug release rate (dM $\mathbf{t} / \mathbf{d t}$ ) $^{-0.5}$ \\
\hline 0.5 & Fickian diffusion & $\mathrm{t}^{-0.5}$ \\
$0.45<\mathrm{n}=0.89$ & Non-Fickian diffusion & $\mathrm{t}^{\mathrm{n}-1}$ \\
0.89 & Case II transport & Zero order (time independent) release \\
Higher than 0.89 & Super case II transport & $\mathrm{t}^{\mathrm{n}-\mathrm{t}}$ \\
\hline
\end{tabular}

\section{RESULTS AND DISCUSSION}

The metformin loaded lower density microsphere were prepared by emulsification $(\mathrm{o} / \mathrm{w})$ solvent evaporation method according to the above-described method by varying concentration of polymers (HPMC, eudragit) and metformin.

\section{Characterization of floating microspheres}

\section{\% Yield and particle size}

The particle size of the optimized formulation was determined by the optical microscopy. The \% yield and particle size of the formulations found to be b/w 70.5 to $86.8 \%$ and 397.73 to $628.27 \mu \mathrm{m}$. The microspheres formulation F1, F2 was not formed completely only some particles appeared in solution. After filtration, the clumps of the microsphere adhere on the filter paper and not rigid and stable. It was due to less concentration of HPMC. As the concentration of HPMC increased in formulation F3 and F4 the microspheres were formed with good yield and particle size values of F3 $(72.9 \%, 397.73 \mu \mathrm{m})$ and F4 $(81.1 \% 415.47 \mu \mathrm{m})$ respectively. On further increasing the HPMC concentration in formulation F5, the yield was found to be decreased but particle size was increase. Due to softness and aggregation of the microsphere with each other and adhere on filter paper again due to the high concentration of HPMC. Finally F3 and F4 blank microsphere which ratio HPMC: Eudragit (7:1) were appropriate for rigid and stable microsphere so here F3 and F4 blank microsphere selected to be loaded with metformin hydrochloride in formulation F6 to F10. On loading with $100 \mathrm{mg}$ drug, F7 was found to have a better yield than F6 but the particle size increase with drug concentration. On further increasing the drug amount to $150 \mathrm{mg}$ in $\mathrm{F} 8$ the \% yield was found to be increased. But afterward, the \% yield was found to be constant with increasing in the drug amount due to saturation of formulation. According to Patel B. et al., they also justified that increases the polymer concentrations then increase the $\%$ yield as well as particle size up to a level [31]. The maximum \% yield was found to be of formulation F8 as results shown in table 3.

\section{\% Buoyancy of the formulation}

The \% buoyancy depends on the density of HPMC and eudragit and drug in stomach contents $0.1 \mathrm{~N}$ HCL. The density of excipient and drug was less hence microspheres float on $0.1 \mathrm{~N}$ HCL. The $\%$ buoyancy of formulation F3 to F9 was found to be b/w 72.33 to $87.67 \%$. The \% buoyancy of blank F3 and F4 was high as compare to other formulation due to the less concentration of both excipients. And when gradually increase the concentration of HPMC with drug the \% buoyancy decrease. Formulation F7 and F8 were found to have \% buoyancy of 81.33 to $80.67 \%$, respectively that was good as compared to other drug loaded formulation. The \% buoyancy proves that the microsphere float in the stomach for a long time and worked as a gastro retentive drug delivery reservoirs [32]. The \% buoyancy shows in the table 3.

Table 3: \%Yield, particle size and buoyancy of drug loaded microspheres

\begin{tabular}{llll}
\hline Formulation & \% Yield & Particle size $(\boldsymbol{\mu m})$ & \% Buoyancy \\
\hline F3 & $72.9 \pm 0.56$ & $397.73 \pm 23.22$ & $85.67 \pm 0.58$ \\
F4 & $81.1 \pm 0.86$ & $415.47 \pm 19.13$ & $87.67 \pm 0.58$ \\
F5 & $70.5 \pm 0.65$ & $628.27 \pm 30.72$ & $72.33 \pm 1.53$ \\
F6 & $75.0 \pm 0.80$ & $438.72 \pm 24.43$ & $77.67 \pm 0.58$ \\
F7 & $84.4 \pm 0.66$ & $476.27 \pm 11.61$ & $81.33 \pm 1.53$ \\
F8 & $86.8 \pm 0.66$ & $526.93 \pm 11.61$ & $80.67 \pm 1.15$ \\
F9 & $79.2 \pm 1.21$ & $567.47 \pm 24.43$ & $75.33 \pm 0.58$ \\
F10 & $82.2 \pm 1.06$ & $595.33 \pm 15.82$ & $69.67 \pm 1.53$ \\
\hline
\end{tabular}

Data are presented as mean $\pm \operatorname{SD}(n=3)$

\section{Drug loading and drug entrapment}

The \% Drug loading and \% entrapment efficiency of the formulation were found to be b/w 11.10 to $17.04 \%$ and 60.02 to $95.30 \%$ respectively. Out of the five drug-loaded formulations (F6-F10), the formulation F8 was found to have a maximum \% drug loading $(17.04 \%)$ and maximum \% entrapment efficiency (95.30\%). The \% drug loading and \% entrapment efficiency were found to be decreased with an increase in the amount of drug to be loaded beyond $150 \mathrm{mg}$ (F8) i.e. F9, F10 due to the saturation of the microspheres with the drug $[33,34]$. The Drug loading and entrapment efficacy of formulations were determined by the direct extraction method and the results are shown in table 4 .

\section{Micromeritic properties}

All the micrometric properties were found in an acceptable range. The compressibility index of the formulations (F6, F7, F8, and F10) was found range between (7.04 to $20.00 \%$ ) have excellent flow-ability and the formulation F9, found to have fair flow-ability. The angle of repose of all the formulations range from (18.147 to $27.47 \%$ ) showed excellent flow property [35]. The results are shown in table 4.

Table 4: Drug loading, entrapment efficiency and micromeritic properties of drug-loaded microspheres

\begin{tabular}{|c|c|c|c|c|c|c|}
\hline S. No. & \%drug loading & $\begin{array}{l}\text { \%entrapment } \\
\text { efficiency }\end{array}$ & $\begin{array}{l}\text { Bulk density } \\
(\mathrm{g} / \mathrm{ml})\end{array}$ & $\begin{array}{l}\text { Tapped density } \\
(\mathrm{g} / \mathrm{ml})\end{array}$ & Compressibility index & $\begin{array}{l}\text { Angle of repose } \\
(\theta)\end{array}$ \\
\hline F6 & $14.30 \pm 0.54$ & $83.49 \pm 1.33$ & $0.75 \pm 0.01$ & $0.86 \pm 0.01$ & 12.79 & 18.15 \\
\hline F7 & $11.10 \pm 0.75$ & $87.43 \pm 1.97$ & $0.73 \pm 0.04$ & $0.84 \pm 0.01$ & 13.10 & 24.26 \\
\hline F8 & $17.04 \pm 0.43$ & $95.30 \pm 0.49$ & $0.66 \pm 0.02$ & $0.71 \pm 0.02$ & 7.04 & 21.80 \\
\hline F9 & $15.58 \pm 0.62$ & $68.43 \pm 1.29$ & $0.76 \pm 0.01$ & $0.95 \pm 0.02$ & 20.00 & 27.47 \\
\hline 10 & $13.31 \pm 0.47$ & $60.02 \pm 1.65$ & $0.71 \pm 0.03$ & $0.81 \pm 0.01$ & 12.35 & 25.91 \\
\hline
\end{tabular}

Data are presented as mean \pm SD $(n=3)$ 


\section{Optimization of formulation}

The formulation F8 was optimized based on \% yield, buoyancy, \% drug loading, \% entrapment efficiency and micrometric properties because formulation F8 shows the good \% yield (86.8\%), \% buoyancy $(80.67 \%), \%$ drug loading $(17.04 \%), \%$ entrapment efficiency $(95.30 \%)$ as compare to other formulation. Further studies i.e. FTIR study, SEM, X-RD and drug release were performed on the optimized formulation (F8) that was finally optimized by the above parameters.

\section{Drug polymer compatibility study}

\section{FTIR study}

FT-IR spectra were recorded to assess the compatibility of the pure drug with other excipients present in the formulation. The FT-IR spectrum of optimized microspheres formulation F8 was recorded separately and compared with the spectrum of pure drug, HPMC, eudragit, blank formulation to verify the possible interaction between the constituent and the characteristic peaks. The main peak of Metformin hydrochloride bands was $\mathrm{N}-\mathrm{H}$ (stretching) $-3365.04 \mathrm{~cm}$ ${ }_{1}^{1}, \mathrm{~N}-\left(\mathrm{CH}_{3}\right)_{2}-3140.87 \mathrm{~cm}^{-1}, \mathrm{C}-\mathrm{N}-930.38 \mathrm{~cm}^{-1}$ and $\mathrm{N}-\mathrm{H}$ (bending) -1622.37 $\mathrm{cm}^{-1}$ was present in drug spectra but absent in the blank formulation because drug was absent in blank, and drug-loaded microspheres exhibited all the characteristics of absorption bands as that of drug metformin hydrochloride without any prominent changes and the FT-IR spectra shows that the drug has not gone through any kind of interactions with the excipient as well as formulation [36]. The FTIR spectra of drug and other excipient shown in fig. 2.

\section{X-RD study}

The effect of the crystallinity of the optimized formulation was recorded by using an X-ray diffractometer. From the study, it was observed that Metformin hydrochloride showed sharp crystalline peaks clearly visible at the position between $15-18{ }^{\circ}(2 \theta)$ shown in fig. 3 which shows the crystalline nature of the drug. The polymer gave the broad spectrum peak that showed the amorphous nature of the polymer. The diffract gram of the metformin-loaded microsphere formulation (F8) showed diminished intensities of peak indicating that the drug was molecularly disbursed in the polymeric matrix or might have undergone amorphization during the preparation of the microspheres. The compatibility study confirmed that Metformin hydrochloride was compatible with other excipient and doesn't get al. tered during formulation of microsphere, was the show in fig. 3.

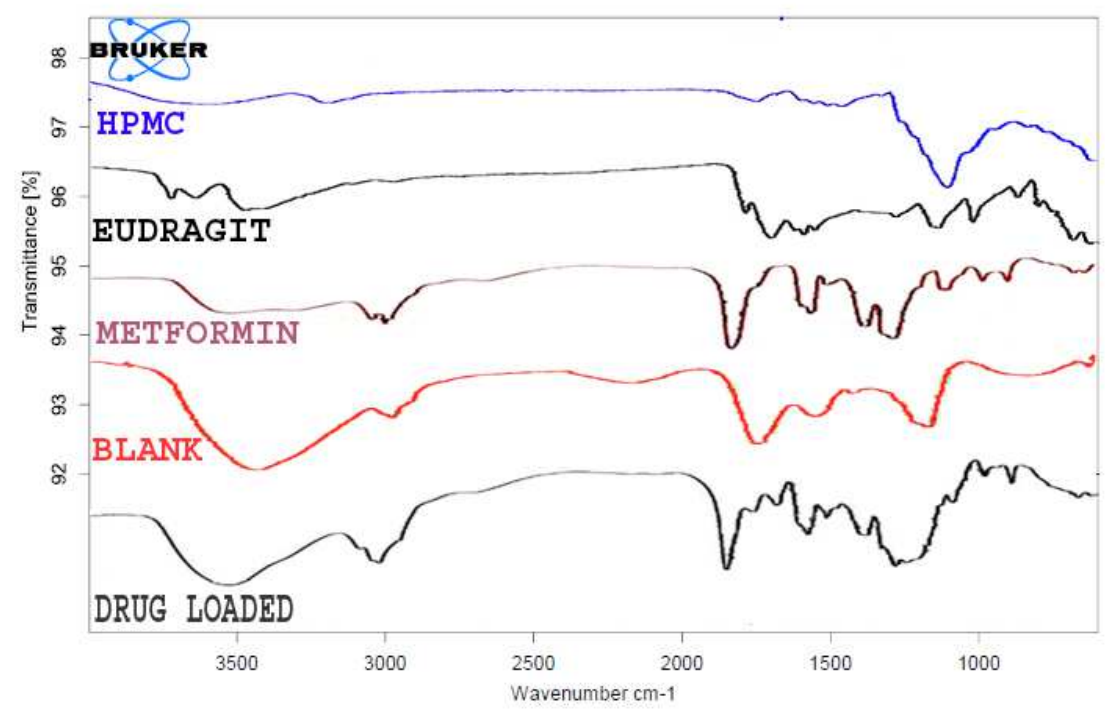

Fig. 2: FT-IR spectrum of HPMC, EudragitS100, Metformin hydrochloride, blank floating microspheres and optimized drug-loaded microspheres (F8)

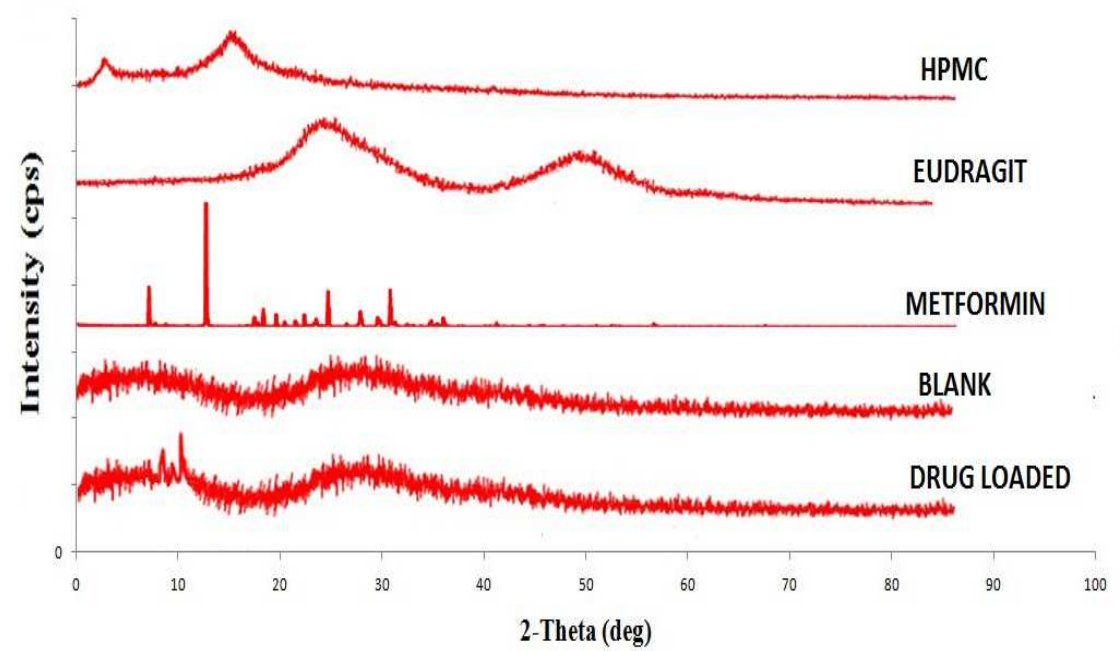

Fig. 3: X-RD of HPMC, eudragit, metformin hydrochloride, blank floating microspheres and optimized drug-loaded microspheres (F8) 


\section{SEM (scanning electron microscopy)}

The shape and surface characteristics of metformin-loaded microsphere optimized formulation (F8) were determined by scanning electron microscope (SEM). The shape of the microsphere was found spherical with a rough surface and the microspheres were solid without any porous on the surface. The agglomeration of microspheres was not seen because of the rigid nature of microspheres [37]. The SEM photograph of microspheres is shown in fig. 4.
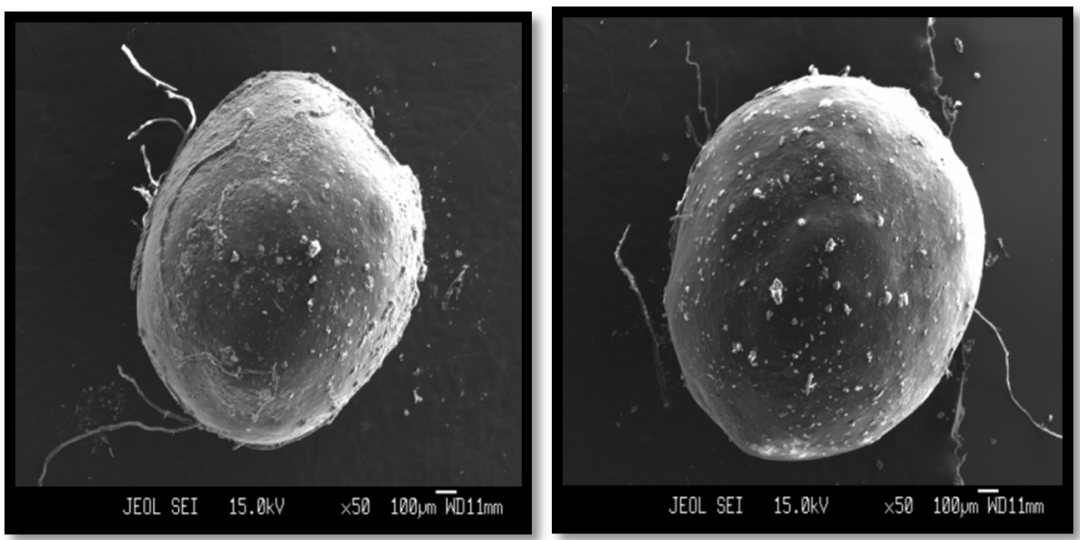

Fig. 4: SEM of the metformin hydrochloride loaded microspheres

\section{In vitro drug release study}

The in vitro drug release study demonstrated that metformin-loaded microsphere optimized formulation (F8) showed maximum drug release $(96.48 \%)$ in the gastric $\mathrm{pH} 0.1 \mathrm{~N} \mathrm{HCl}$ up to $24 \mathrm{~h}$ and the sample was analyzed in triplicate. The in vitro study of optimized formulations (F8) was performed by using USP Dissolution Test Apparatus Type 1 (Basket Type) in the $0.1 \mathrm{~N} \mathrm{HCl}$. The drug release profile of optimized formulation (F8) was release the drug in a controlled manner for a long time that shows the formulation F8 was work as a controlled drug delivery system and give high bioavailability [38]. The result of the release study is shown in fig. 5.

\section{Formulation F8}

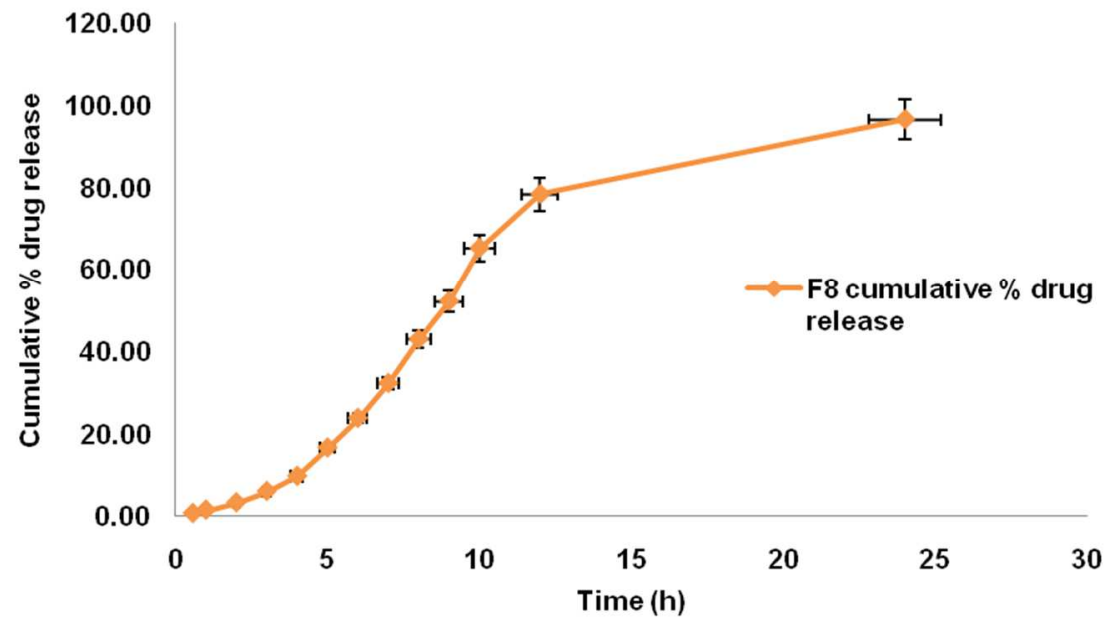

Fig. 5: Drug release graph of optimized formulation (F8) data points represented mean $\pm S D(n=3)$

\section{In vitro drug release kinetics}

The data obtained from in vitro release study were fitted to various kinetic equations to find out the mechanism of drug release from the optimized drug loaded formulation (F8). The kinetic models used were a zero-order equation, first-order equation, Higuchi model and Korsmeyer-Peppas model. Drug release kinetics was best fitted to the
Korsmeyer-peppas model as the $\mathrm{R}^{2}$ value for the model was 0.971 which was very closer to 1 , than the other $\mathrm{R}^{2}$ value of other models. The drug release mechanism was of Super case II transport as the release exponent, the drug get the release from the microsphere by erosion system, the ' $n$ ' value was found to be 1.490 which was greater than 1. The graphical representation of different kinetic models of in vitro drug release profile is shown in fig. 6 to 9 and table 5 .

Table 5: Release kinetics of optimized formulation F8

\begin{tabular}{lllll}
\hline Formulation code & Zero order & First order & Higuchi model & Korsmeyer-peppas \\
\cline { 2 - 5 } & $\left(\mathbf{R}^{2}\right)$ value & $\left(\mathbf{R}^{2}\right)$ value & $\left(\mathbf{R}^{2}\right)$ value & \\
\hline F-8 & 0.879 & 0.953 & 0.903 & 0.971 \\
\hline
\end{tabular}




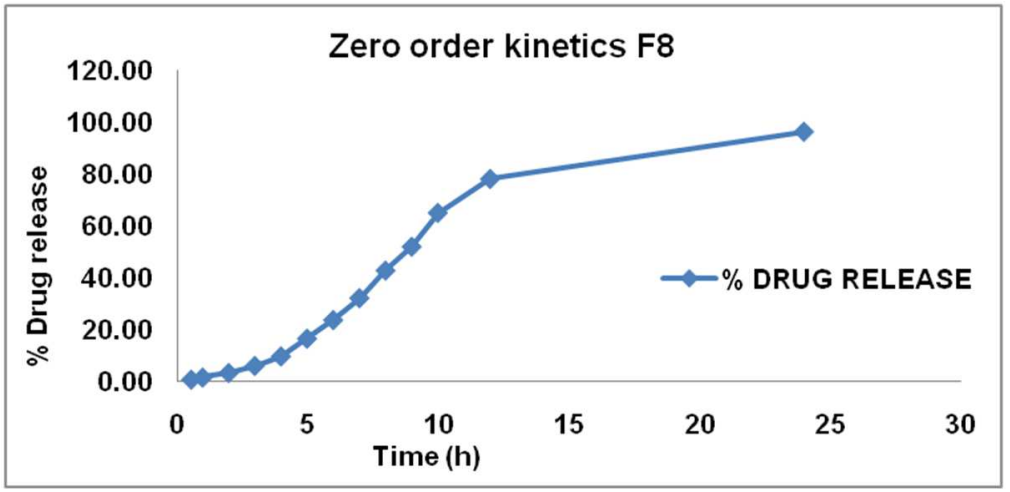

Fig. 6: Zero-order kinetics of optimized formulation (F8)

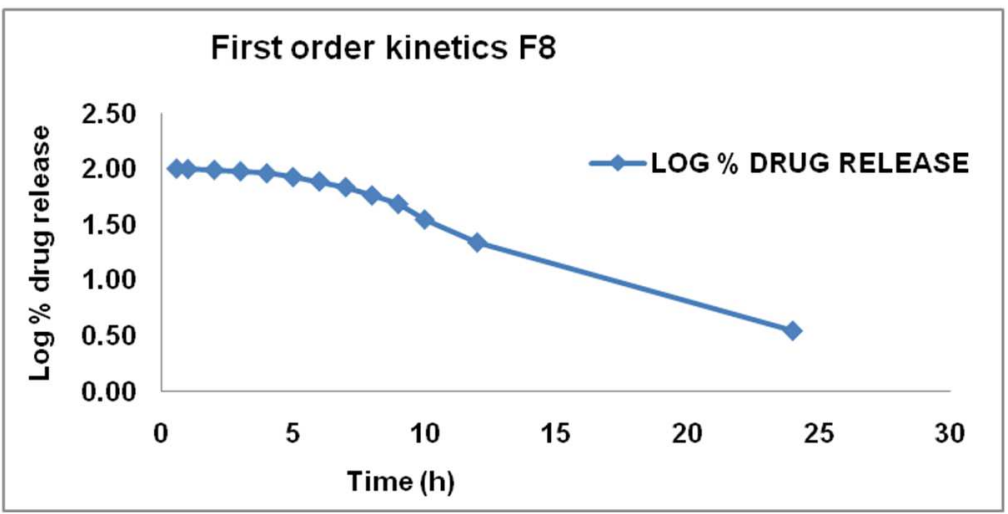

Fig. 7: First order kinetics of optimized formulation (F8)

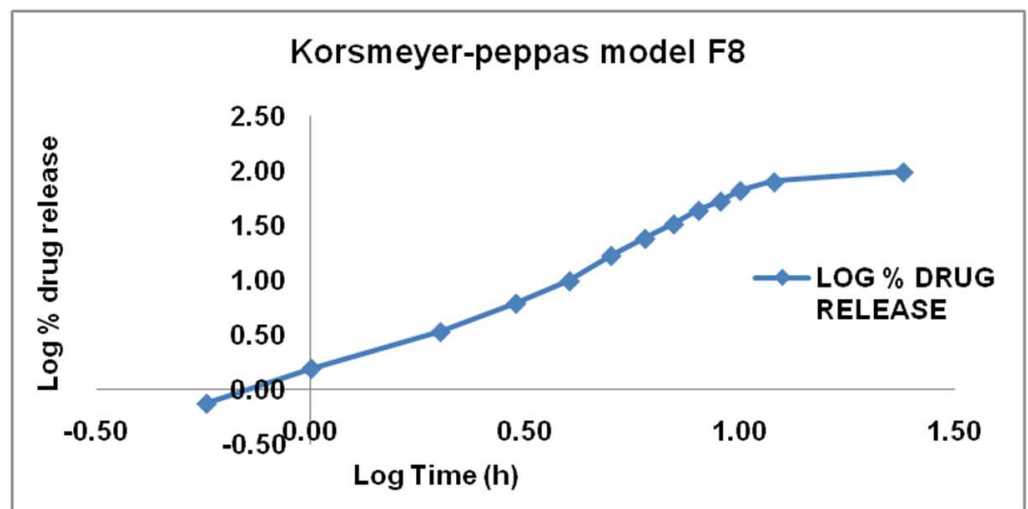

Fig. 8: Korsmeyer-peppas model of optimized formulation (F8)

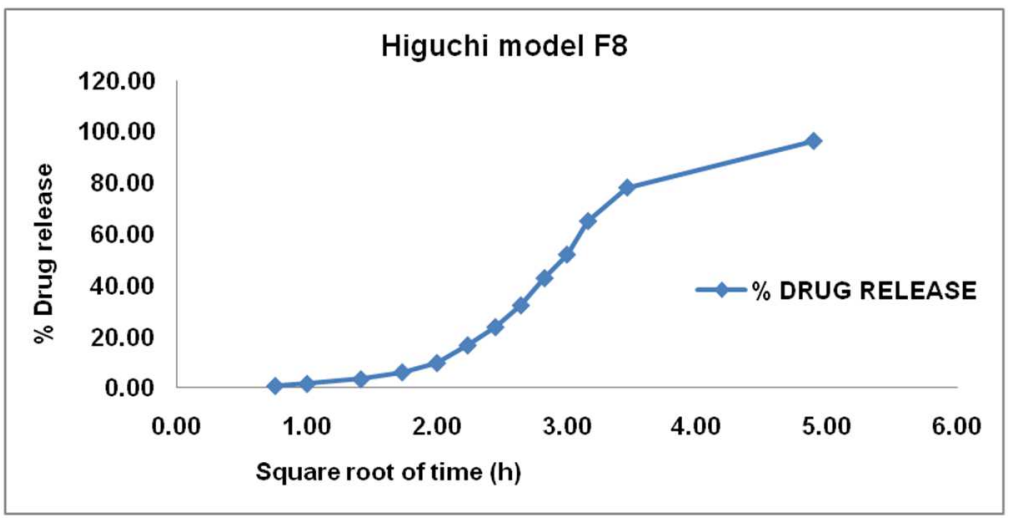

Fig. 9: Higuchi model of optimized formulation (F8) 


\section{CONCLUSION}

The HPMC and eudragit S100 blend microspheres loaded with metformin hydrochloride were formulated successfully by using a modified solvent evaporation method and optimized the F8 formulation by different parameters like \% yield, buoyancy, \% drug loading, \% entrapment efficiency and micrometric properties. The $\%$ yield, $\%$ buoyancy, $\%$ drug loading and $\%$ entrapment efficiency was found to be of optimized formulation F8 84.4\%, 80.67\%, 17.04\% and $95.30 \%$ respectively. The $\%$ yield was decreased with increasing the drug concentration and the \% buoyancy was affected by changing the ratio of polymer and drug. The \% drug loading and \% entrapment efficiency decreased with an increase in the amount of drug to be loaded beyond $150 \mathrm{mg}$ i.e. F9, F10 due to saturation of the microspheres with the drug. The FTIR spectrum of optimized formulation F8 showed that there was no chemical interaction and drug was compatible with polymer. The sharp peak of Metformin hydrochloride was also appearing in optimized formulation F8, which revealed the drug incorporate into the microspheres. The SEM study of formulation F8 with nearly spherical shape and a rough surface without any pore. The formulation F8 release the 96\% drug in $24 \mathrm{~h}$ that shows the formulation F8 was work as a controlled drug delivery system. Drug release kinetics of F8 formulation was best fitted for the Korsmeyer-peppas model and the drug release mechanism was of super case-2 transport. In which drug release by erosion mechanism.

\section{FUNDING}

Nil

\section{AUTHORS CONTRIBUTIONS}

Dr. Alok Mukerjee was a principle of my college United institute of pharmacy Allahabad, and also my project guide. Mukerjee Sir gives me a strong platform to perform this project. With the help of Mukerjee Sir my college provided funding for the study, statistical support in analyzing data and for instrumental analysis.

Mr. Amit Kumar Singh worked as my co-guide. Singh Sir designed and conducted the study, data collection and data analysis and also helped me for manuscript designing.

Mr. Pankaj Kumar Jaiswal worked as my colleague. He helped me in every step of my unit process and participated in the sequence alignment and drafted the manuscript with me. He carried out the SEM and DSC analysis from the outside of college and helped me in the interpretation of data. And also give me moral support.

I am Shikha Kesharvani carried out all works related to this project with the help of my guide, co-guide and my colleague. And prepare all data that present in this manuscript and also design and sequence alignment and drafted all things in this manuscript.

All authors approved the final manuscript.

\section{CONFLICT OF INTERESTS}

The authors declare that they have no conflict of interest.

\section{REFERENCES}

1. Rouge N, Buri P, Doelker E. Drug absorption sites in the gastrointestinal tract and dosage forms for site-specific delivery. Int J Pharma 1996;136:117-39.

2. Streubel A, Siepmann J, Bodmeier R. Gastroretentive drug delivery system. Expert Opin Drug Delivery 2006;3:217-33.

3. Iannucelli V, Coppi G, Bernabei MT, Camerorni R. Air compartment multiple-unit system for prolonged gastric residence part-Iformulation study. Int J Pharm 1998;174:47-54.

4. Rouge N, Allemann E, Gex-Fabry M, Balant L, Cole ET, Buri P, et al. Comparative pharmacokinetic study of a floating multipleunit capsule, a high-density multiple unit capsule and an immediate-release tablet containing $25 \mathrm{mg}$ atenolol. Pharm Acta Hel Betiae 1998;73:81-7.

5. Streubel A, Siepmann J, Bodmeier R. Multiple units gastro retentive drug delivery: a new preparation method for lowdensity microparticles. J Microencapsule 2003;20:329-47.

6. Goole J, Vanderbist F, Aruighi K. Development and evaluation of new multiple-unit levodopa sustained-release floating dosage forms. Int J Pharm 2007;334:35-41.
7. Shrma S, Pawar A. Low-density multiparticulate system for pulsatile release of meloxicam. Int J Pharm 2006;313:150-8.

8. Santus G, Lazzarini G, Bottoni G, Sandefer EP, Page RC, Doll WJ, et al. An in vitro-in vivo investigation of oral bioadhesive controlled release furosemide formulations. Eur J Pharm Biopharm 1997;44:39-52.

9. Klausner EA, Lavy E, Friedman M, Hoffman A. Expandable gastro retentive dosage forms. J Controlled Release 2003;90:143-62.

10. Deshpande AA, Shah N, Rhodes CT, Malik W. Development of a novel controlled-release system for gastric retention. Pharm Res 1997;14:815-9.

11. Park K. Enzyme-digestible swelling as platforms for longterm oral drug delivery: synthesis and characterization. Biomaterials 1988;9:435.

12. Fujimori J, Machida Y, Nagai T. Preparation of a magneticallyresponsive tablet and configuration of its gastric residence in beagle dogs. STP Pharma Sci 1994;4:425-30.

13. Kawashima Y, Niwa T, Takeuchi H, Hino T, Itoh Y. Hollow microspheres for use as a floating controlled drug delivery system in the stomach. J Pharm Sci 1992;81:135-40.

14. Lee HJ, Park GT, Choi KH. Development of oral drug delivery system using floating microspheres. J Microencapsulation 1999;16:715-29.

15. Obeidat WM, Price JC. Evaluation of enteric matrix microspheres prepared by emulsion-solvent evaporation using scanning electron microscopy. J Microencap 2004;21:47-57.

16. Subrahmanyam CVS. Textbook of physical pharmaceutics. $2^{\text {nd }}$ ed. Mumbai, India: Vallabh Publication; 2002.

17. Patel A, Ray S, Thakur SR. In vitro evaluation and optimization of controlled release floating drug delivery system of metformin hydrochloride. DARU 2006;14:57-64.

18. Subham B, Gaurav C, Dilip KP. Investigation on cross-linking density for development of novel interpenetrating polymer network (IPN) based formulation. J Sci Ind Res 2010;69:777-84.

19. Swamy SEK, Goud AB. Formulation and evaluation of sustainedrelease acelofenac microspheres. J Adv Pharm Sci 2012;2:155-66.

20. Shariff A, Manna PK, Paranjothy KL. Entrapment of andrographolide in cross-linked alginate pellets: I. formulation and evaluation of associated release kinetics. Pakistan J Pharm Sci 2007;20:1-9.

21. Ranjha NM, Khan H, Naseem S. Encapsulation and characterization of controlled release flurbiprofen loaded microspheres using beeswax as an encapsulating agent. J Mater Sci Mater Med 2010;21:1621-30.

22. Patel R, Bhimani D, Patel J, Patel D. Solid-state characterization and dissolution properties of ezetimibe-cyclodextrins inclusion complexes. J Incl Phenom Macrocyclic Chem 2008;60:241-51.

23. Mohamed MN, Khaleid MA, Mohamed AS. formulation and evaluation of extended-release metformin hydrochloride beads. Int J Pharm Pharm Sci 2010;6:433-41.

24. Senthil SK, Jaykar B, Kavimani S. Formulation, characterization and in vitro evaluation of floating microsphere containing rabeprazole sodium. J Inn Tre Pharm Sci 2010;1:274-82.

25. Bhardwaj P, Chaurasia D, Singh R, Swarup A. Development and characterization of novel site-specific hollow floating microspheres bearing 5-fu for stomach targeting. Sci World J 2014. http://dx.doi.org/10.1155/2014/705259

26. Kamel HA, Sokar SM, Gamal SS, Naggar FV. Preparation and evaluation of ketoprofen floating oral delivery system. Int J Pharm 2001;220:13-21.

27. Narasimha SDP, Murthay NL, Chowdhury P. Kinetic modelling on drug release from controlled drug delivery system. Acta Pharm 2010;67:217-23.

28. Suleiman NN. The kinetics of drug release from ethylcellulose solid dispersions. Drug Dev Ind Pharm 1985;11:2169-81.

29. Simonelli DS, Higuchi W. Investigation of factors influencing release of solid drug dispersed in inert matrices. J Pharm Sci 1965;54:1459-64.

30. Higuchi T. Mechanism of sustained action medication. Theoretical analysis of the rate of release of solid drugs dispersed in solid matrices. J Pharm Sci 1963;52:1145-9.

31. Patel B, Modi V, Patel K, Patel M. Preparation and evaluation of ethyl cellulose microspheres prepared by an emulsification- 
solvent evaporation method. Int I Res Management Pharm 2012;1:82-91.

32. Vaghani S, Vasanti S, Chaturvedi K, Satish CS. Stomach-specific drug delivery of 5-fluorouracil using ethylcellulose floating microspheres. Pharm Dev Technol 2010;15:154-61.

33. Farooq U, Khan S, Nawaz S, Ranjha NM. Enhanced gastric retention and drug release via the development of novel floating microspheres based on Eudragit E100 and polycaprolactone: synthesis and in vitro evaluation. Des Monomers Polym 2017;20:419-33.

34. Choudhury PM, Kar M, Chauhan SC. Cellulose acetate microspheres as floating depot systems to increase gastric retention of antidiabetic drug: formulation, characterization and in vitro-in vivo evaluation. Drug Dev Ind Pharm 2008;34:349-54.
35. Ershad S, Sai KV, Kartheek U, Sandeep M, Prameela Rani K Preparation and evaluation of floating microspheres of ritonavir. J Pharm Pharm Sci 2014;3:5-11.

36. Mahaveer DK, Tejraj MA. Poly (vinyl alcohol) and poly (acrylic acid) sequential interpenetrating network $\mathrm{pH}$-sensitive microspheres for the delivery of diclofenac sodium to the intestine. J Controlled Release 2004;96:9-20.

37. Sharma M. In vitro and in vivo evaluation of repaglinide loaded floating microspheres prepared from different viscosity grades of HPMC polymer. Saudi Pharm J 2015. Doi:10.1016/ j.jsps.2015.02.013

38. Dubey M, Kesharwani P, Tiwari A, Chandel R. Formulation and evaluation of floating microsphere containing an anti-diabetic drug. Int J Pharm Chem Sci 2012;1:1038-47. 